\title{
NOTAS INTRODUTÓRIAS SOBRE GESTÃO ESCOLAR NA PERSPECTIVA DA PEDAGOGIA HISTÓRICO-CRÍTICA
}

\author{
Luciana Cristina Salvatti Coutinho ${ }^{1}$ \\ José Claudinei Lombardi ${ }^{2}$
}

\section{RESUMO}

Esse texto busca apresentar, de forma introdutória, algumas reflexões de caráter teórico acerca da gestão da escola fundamentando-se nos pressupostos da Pedagogia históricocrítica (PHC) nos quais nossas ações enquanto gestores se sustentaram. Não se trata, portanto, de um relato de experiência mas sim de um esforço de contribuir para a elaboração teórica da PHC. A fim de dar conta do objetivo exposto, a argumentação será dividida em quatro partes: uma introdução na qual abordar-se-á, de forma sintética, os conceitos de trabalho e administração de modo geral, bem como o papel do Estado na modernidade. Em seguida, explicitar-se-á o significado e sentido da educação a partir dos pressupostos da Pedagogia histórico-crítica e a consequente necessidade de organização coletiva intencional do trabalho educativo para se efetivar o processo de humanização dos seres humanos. Num terceiro momento, serão identificados alguns elementos na própria organização do Estado e da escola na contemporaneidade que limitam a concretização de um trabalho coletivo intencional resultado, dentre outros aspectos, da transposição das teorias científicas da administração ao campo educacional por meio do Estado. A título de conclusão, a partir da e na própria estrutura educacional vigente buscar-se-á apontar algumas possibilidades reais de um trabalho pedagógico consciente e coerentemente organizado pelo conjunto dos educadores que implicam, contudo, em uma pauta de luta mais efetiva e orgânica por melhores condições de formação e trabalho, assim como a criação efetiva de mecanismos de controle social da gestão pública.

Palavras-chave: Educação brasileira; Pedagogia histórico-crítica; gestão escolar

\section{INTRODUCTORY NOTES ON SCHOOL MANAGEMENT IN PERSPECTIVE OF HISTORICAL-CRITICAL PEDAGOGY}

\begin{abstract}
This text aims, in an introductory way, some theoretical character of reflections on the school management is basing at historical-critical pedagogy (PHC) in which our actions as managers are supported. It is not, therefore, an account of experience but rather an effort to contribute to the theoretical development to PHC. The argument will be divided into four parts: an introduction in which will be addressed, synthetically, the concepts of work and general administration as well as the role of the state in modern times. Then explain shall be the significance and meaning of education from the assumptions of historical-critical pedagogy and the consequent need for intentional collective organization of educational work to carry out the process of humanization of human beings. Thirdly, they will be identified some elements in the organization of the state and school in the present that limit the realization of an intentional collective work result, among other things, implementation of scientific theories of management to the educational field through the state. In conclusion, fromtheandowncurrenteducationalstructure will be sought to point out some real possibilities of educational work consciously and coherently organized by all the educators who imply, however, in an agenda more effectively and organic struggle for better conditions for training and work, as well as the creation of effective mechanisms of social control of public management.
\end{abstract}

Keywords: Brazilianeducation; historical-criticalpedagogy; schoolmanagement 


\section{Introdução}

As análises aqui elaboradas tiveram como ponto de partida os desafios enfrentados na gestão educacional na Secretaria Municipal de Educação de Limeira, cidade do interior do Estado de São Paulo, na qual atuamos durante dois anos e nos quais se buscou fomentar mudanças no trabalho pedagógico e, consequentemente, na gestão da educação, de modo geral, e da escola, especificamente.Assim, esse texto busca apresentar, de forma introdutória, algumas reflexões de caráter teórico acerca da gestão da escola fundamentando-se nos pressupostos da Pedagogia histórico-crítica (PHC) nos quais nossas ações enquanto gestores se sustentaram. Não se trata, portanto, de um relato de experiência mas sim de um esforço de contribuir para a elaboração teórica da PHC.

A Pedagogia histórico-crítica, no quadro das teorias pedagógicas, assume uma posição crítica contra-hegemônica como arma teórica contra o modo de produção capitalista, rumo a uma sociedade de fato justa e igualitária na qual a educação tenha como horizonte o pleno desenvolvimento dos seres humanos por meio da apropriação da cultura produzida histórica e coletivamente pela humanidade.

Tendo como referência, portanto, a concepção pedagógica histórico-crítica, a partir do início de 2013 iniciamos nosso trabalho na Secretaria Municipal de Educação de Limeira, na condição de Secretário de Educação (José Claudinei Lombardi) e Diretora Pedagógica (Luciana Cristina Salvatti Coutinho), objetivando desencadear um processo de (re)estruturação da Rede Pública Municipal de Ensino buscando direcioná-la no sentido de proporcionar uma formação de qualidade aos alunos que, em sua maioria, são os filhos da classe trabalhadora limeirense. Nesse curto percurso, muitos encaminhamentos práticos foram propostos a partir dos problemas detectados, bem como muitos questionamentos foram suscitados que exigem elaboração teórica por parte dos pesquisadores que se fundamentam na pedagogia histórico-crítica. Um desses desafios diz respeito à necessidade de buscar objetivar uma gestão que, efetivamente, busque alavancar um trabalho coletivo intencional que, de forma incansável, tenha em vista a finalidade de "produzir, direta e intencionalmente, em cada indivíduo singular, a humanidade que é produzida histórica e coletivamente pelo conjunto dos homens"(SAVIANI, 2005, p. 7), na forma de respostas práticas aos limites impostos pela estrutura político-jurídica e administrativa do aparelho do Estado.

A fim de dar conta do objetivo exposto, a argumentação será dividida em quatro partes: uma introdução na qual abordar-se-á, de forma sintética, os conceitos de trabalho e administração de modo geral, bem como o papel do Estado na modernidade. Em seguida, explicitar-se-á o significado e sentido da educação a partir dos pressupostos da Pedagogia histórico-crítica e a consequente necessidade de organização coletiva intencional do trabalho educativo para se efetivar o processo de humanização dos seres humanos. Num terceiro momento, serão identificados alguns elementos na própria organização do Estado e da escola na contemporaneidade que limitam a concretização de um trabalho coletivo intencional resultado, dentre outros aspectos, da transposição das teorias científicas da administração ao campo educacional por meio do Estado. A título de conclusão, a partir da e na própria estrutura educacional vigente buscar-se-á apontar algumas possibilidades reais de um trabalho pedagógico consciente e coerentemente organizado pelo conjunto dos educadores que implicam, contudo, em uma pauta de luta mais efetiva e orgânica por melhores condições de formação e trabalho, assim como a criação efetiva de mecanismos de controle social da gestão pública. 


\section{Uma discussão teórica preliminar: Trabalho, Administração, Estado}

Para se compreender a história da humanidade e o conjunto de suas realizações produzidas ao longo desse processo que formam um mundo propriamente humano faz-se necessário, segundo Saviani (2005), compreender a natureza humana.

Aos seres humanos, para sobreviver, impõe-se a necessidade de produzir sua própria existência material agindo, de forma intencional e ativamente, sobre a natureza, transformando-a de acordo com suas necessidades. É possível afirmar, assim, que a ação dos homens sobre a natureza é adequada às finalidades por eles estabelecidas. Num primeiro momento, cumpre satisfazer as necessidades mais elementares para a subsistência. Da satisfação dessas necessidades primárias, outras surgem cada vez mais "humanizadas", ou seja, como resultado das transformações efetivadas pelos homens sobre a natureza. Como afirma Saviani (2005, p. 11):

Para sobreviver, o homem necessita extrair da natureza, ativa e intencionalmente, os meios de sua subsistência. Ao fazer isso, ele inicia o processo de transformação da natureza, criando um mundo humano (o mundo da cultura).

Na práxis social, assim, o trabalho se constitui como instrumento por meio do qual os seres humanos produzem sua existência. Este, o trabalho, como atividade vital humana, se estrutura em dois elementos interdependentes e indissociáveis: de um lado a projeção, no plano do pensamento, do conjunto de ações a serem efetivadas que melhor se apresentam, aos sujeitos, como instrumentos para se alcançar as finalidades estabelecidas e, de outro, as ações propriamente ditas, tal como esclarece Marx (2013, p. 255-256):

Uma aranha executa operações semelhantes às do tecelão, e a abelha envergonha muitos arquitetos com a estrutura de sua colmeia. Porém, o que desde o início distingui o pior arquiteto da melhor abelha é o fato de que o primeiro tem a colmeia em sua mente antes de construí-la com a cera. No final do processo de trabalho, chega-se a um resultado que já estava presente na representação do trabalhador no início do processo, portanto, um resultado que já existia idealmente.

Nos seus elementos mais simples é possível afirmar, como o faz o autor acima referido, que o processo de trabalho se constitui de três elementos que compõem juntos uma unidade dialética: a atividade propriamente dita, o objeto sobre o qual a ação ou conjunto de ações se dirigem e os meios selecionados dentre os quais se dispõem para que se atinja determinado objetivo. Esses meios utilizados para a consecução de uma atividade com vistas a determinada finalidade compreendem um ou mais elementos que medeiam a relação dos homens com o objeto de sua ação servindo-lhes, portanto, de guia para realização dos objetivos projetados. "No processo de trabalho, portanto, a atividade do homem, com ajuda dos meios de trabalho, opera uma transformação do objeto do trabalho segundo uma finalidade concebida desde o início"(idem, p. 258).

Justamente por se colocar, de forma consciente, objetivos, é que os homens precisam, no processo de trabalho, utilizar racionalmente os instrumentos materiais, teóricos e técnicos dos quais dispõem para alcançar, no menor tempo possível e com o menor dispêndio de recursos, as finalidades pré-estabelecidas. Mas, como alerta Paro (2000, p. 19), 
É conveniente, entretanto, explicitar melhor, ainda que de forma provisória, o que devemos entender por "utilização racional de recursos". A palavra racional vem do latim ratio, que quer dizer razão. Assim, se se tem um fim em mente, utilizar racionalmente os recursos (utilizá-los de acordo com a razão) significa, por um lado que tais recursos sejam adequados ao fim visado, por outro, que seu emprego se dê de forma econômica.

Outro aspecto a ser considerado sobre o processo de trabalho refere-se ao fenômeno que foi se configurando historicamente de que a produção das condições necessárias para a existência humana passou a ser socialmente produzidas exigindo, portanto, a consecução das atividades desenvolvidas por grupos de pessoas. Paro (2000) salienta que, além, portanto, da utilização racional de recursos, deve-se acrescentar a necessidade de coordenação do esforço humano coletivo dos sujeitos inseridos no processo de trabalho.

Cabe, aqui, outro alerta, considerando que na atualidade, via de regra, no tão vangloriado planejamento estratégico, a relação entre o planejamento e a ação propriamente dita vem sendo entendida e traduzida na realidade concreta como mecânica e, mais, de subordinação da prática ao projeto sistematizado. Nesse sentido, Paro (2000) elucida que

O projeto inicial defronta-se com resistências em sua concretização. Ao tentar vencê-las, há a necessidade de sua constante modificação, não só no modo de realizá-lo - modificando, com isso, o processo -, mas também na forma do objeto ideal, resultando, no final, um produto que não será mais idêntico ao inicialmente projetado (p. 27).

Resumindo, o trabalho se constitui como a atividade humana por meio da qual, na sua relação com a natureza e entre si, os homens produzem sua própria existência criando, nesse caminho, um mundo socialmente organizado. $O$ processo de trabalho implica a ação de um coletivo de trabalhadores sobre um objeto visando determinada finalidade e, para tanto, utiliza-se de diferentes instrumentos ou recursos. A administração, portanto, se configura como uma atividade propriamente humana inserida e adequada ao processo de trabalho que, de modo geral, significa a utilização racional dos recursos e a ação coletiva dos trabalhadores intencionalmente estruturada e coordenada tendo em vista a finalidade do processo que exige, por conseguinte, dada sua dinâmica, uma reflexão constante para que as mudanças necessárias sejam efetivadas ao longo do caminho.

No entanto, ressalta-se, o trabalho assume forma concreta específica de acordo com o modo de produção em que se desenvolve. Não se pode esquecer, assim, que, na modernidade, a lógica do capital é imperante e, portanto, fundamento da organização e gestão do processo de trabalho.

Para efeitos do limite de um artigo e para os propósitos que se pretende, cumpre destacar que as finalidades atribuídas ao processo de trabalho nas óticas do Capital e do Trabalho são diametralmente opostas. Para o Capital interessa adequar o processo produtivo ao objetivo de acumulação e concentração de riqueza nas mãos de poucos e, para isso, faz-se necessário criar mecanismos que condicionem o processo de trabalho a essa diretriz confrontando-se, nesse processo, com a resistência dos trabalhadores que, por sua vez, mesmo que, por vezes, sem ter tanta clareza das determinações estruturais e sistêmicas do capitalismo, percebem que estão sendo usados como instrumentos para atendimento de interesses de uma minoria detentora dos meios de produção que não corresponde aos 
interesses e necessidades dos próprios trabalhadores, maioria da população. Em outras palavras, percebe-se que, no processo produtivo, há a apropriação privada dos bens produzidos socialmente do que decorre uma contradição de caráter estrutural entre Capital e Trabalho, constituída sobre as bases da divisão social do trabalho ${ }^{3}$.

É nesse contexto acima referido que é possível entender a forma e o lugar que assume o Estado Moderno, como esclarece Sanfelice (2003, p. 162):

[...] historicamente se torna impossível desvincular o denominado Estado moderno da ordem burguesa e suas contradições subseqüentes. Assim sendo, passa, então, a ser cada vez mais visível que o Estado é capitalista e, mais do que isso, é do capital. O controle do poder político-econômico é exercido pelos proprietários dos meios de produção, não importando aqui o modo como estes estejam aglutinados, cabendo ao Estado fundamentalmente garantir a propriedade privada, entendida como fundamento da liberdade individual. O Estado, portanto, é um partícipe da lógica do capital.

É possível afirmar, portanto, o caráter histórico do Estado ${ }^{4}$ que, na modernidade, assume forma jurídico-política e administrativa adequada às finalidades ditadas pela lógica do Capital cumprindo a tarefa de, para garantir (ou promover) condições necessárias para acumulação de capital e concentração de renda, camuflar a contradição entre os interesses individuais e os coletivos, expressos na luta de classes. Nesse sentido, afirma Engels (1964, p. 135-136):

O Estado não é pois, de modo algum, um poder que se impôs à sociedade de fora para dentro; tampouco é a "realidade da ideia moral", nem "a imagem e a realidade da razão", como afirma Hegel. É antes um produto da sociedade, quando esta chega a um determinado grau de desenvolvimento; é a confissão de que essa sociedade se enredou numa irremediável contradição com ela própria e está dividida por antagonismos irreconciliáveis que não conseguem conjurar. Mas para que esses antagonismos, essas classes com interesses econômicos colidentes não se devorem e não consumam a sociedade numa luta estéril, faz-se necessário um poder colocado aparentemente por cima da sociedade, chamado a amortecer o choque e mantê-lo dentro dos limites da ordem. Este poder, nascido da sociedade, mas posto acima dela se distanciando cada vez mais, é o Estado.

Sendo expressão dos antagonismos estruturais da sociedade erigida sob o modo de produção capitalista, a estrutura, organização e funcionamento da "máquina pública" é marcada por contradições e antagonismos também internos, cuja ação tem sentido apenas "corretivo" e, portanto, relativo e limitado à estrutura social vigente, condicionando tanto sua própria estrutura organizacional, marcadamente fragmentada, bem como regulando a participação e controle social das ações governamentais.

Compreendidos, ainda que de forma sintética, trabalho, administração e Estado em seus elementos gerais apontando que estes são historicamente determinados, cumpre a tarefa de se debruçar sobre a concepção de educação, considerando que se trata, nesse texto, de abordar a questão da Gestão (ou Administração) da Educação, especificamente, da educação pública (estatal). 


\section{A Educação na perspectiva da Pedagogia histórico-crítica}

A educação, segundo Saviani (2005), tal qual o trabalho, se constitui numa atividade propriamente humana e, portanto, acompanha a história da humanidade, num processo de unidade dialética com a atividade (trabalho) por meio da qual se vem produzindo, ao longo do tempo, a existência própria dos homens adquirindo, portanto, características específicas em função das condições econômicas, políticas e sociais de cada momento histórico e em cada formação social. "Dizer, pois, que a educação é um fenômeno próprio dos seres humanos significa afirmar que ela é, ao mesmo tempo, uma exigência do e para o processo de trabalho, bem como é, ela própria, um processo de trabalho" (SAVIANI, 2005, p. 12, grifos nossos).

No processo de produção da própria existência objetivada por meio do trabalho, de acordo com Leontiev (1978, p. 265)

[...] os homens não fazem senão adaptar-se à natureza. Eles modificam-na em função do desenvolvimento das suas necessidades. Criam os objetos que devem satisfazer as suas necessidades e igualmente os meios de produção destes objetos, dos instrumentos às máquinas mais complexas. Constroem habitações, produzem as suas roupas e outros bens materiais. Os progressos realizados na produção de bens materiais são acompanhados pelo desenvolvimento da cultura dos homens; o seu conhecimento do mundo circundante e deles mesmos enriquece-se, desenvolvem-se a ciência e a arte.

Ao transformar a natureza adaptando-a as suas necessidades, os homens não só criam objetos materiais e não materiais como, também, nesse processo, se (trans)formam sobre a base da sua natureza biofísica sendo necessário, portanto, a cada ser humano singular que, ao nascer, se aproprie do acervo cultural produzido pelas gerações precedentes a fim de que se tornem "homens contemporâneos".

Cada geração começa, portanto, a sua vida num mundo de objetos e de fenômenos criados pelas gerações precedentes. Ela apropria-se das riquezas deste mundo participando no trabalho, na produção e nas diversas formas de atividade social e desenvolvendo assim as aptidões especificamente humanas que se cristalizaram, encarnaram nesse mundo. Com efeito, mesmo a aptidão para usar a linguagem articulada só se forma, em cada geração, pela aprendizagem da língua que se desenvolveu num processo histórico, em função das características objetivas desta língua (idem, p. 265-266).

Na sociedade atual, o fato de a burguesia necessitar alavancar o processo produtivo com o intuito de acumular capital impulsionando, para isso, o desenvolvimento dos meios de produção, promove-se um deslocamento do eixo produtivo do campo para a indústria e, consequentemente, para as cidades que se multiplicam pelas várias regiões do mundo nas quais a vida se organiza sob o modo de produção capitalista.

O processo produtivo que se realiza nas indústrias e a vida urbana se organizam por meio de estruturas formais, sistemáticas, com características marcadamente culturais em detrimento das naturais. Nesse contexto, a questão da formação das novas gerações se põe como uma questão problemática pois não é mais possível se dar de forma espontânea e natural no próprio processo de produção da existência material humana como ocorria, por exemplo, nas comunidades primitivas. 
Emerge, assim, a necessidade de organização deliberada do processo formativo dos seres humanos convertendo-a numa questão teórica, de um lado, e prática, de outro, ou seja, a educação se eleva, de forma imperiosa, na sociedade moderna, como uma atividade que necessita ser intencionalmente organizada adequada à finalidade de formação dos seres humanos dessa e para essa sociedade e, para tanto, tem-se início o processo de institucionalização da educação por meio da criação de uma estrutura específica, a escola. A escola surge, portanto, num momento histórico no qual a ciência, conhecimento sistemático pois rigorosa e metodicamente elaborado, se converte em força produtiva provocando modificações em toda a tessitura social.

O nível de desenvolvimento atingido pela sociedade contemporânea coloca a exigência de um acervo mínimo de conhecimentos sistemáticos, sem o que não se pode ser cidadão, isto é, não se pode participar ativamente da vida da sociedade (SAVIANI, 2007, p. 160).

A questão que se coloca, a partir dessa constatação, é a identificação desse acervo mínimo de conhecimentos sistemáticos e, mais, as formas por meio das quais é possível a cada ser humano singular se apropriar desse saber que se configura no currículo escolar. Eis a afirmação de Saviani a esse respeito:

[...] o objeto da educação diz respeito, de um lado, à identificação dos elementos culturais que precisam ser assimilados pelos indivíduos da espécie humana para que eles se tornem humanos e, de outro lado e concomitantemente, descoberta das formas mais adequadas para atingir esse objetivo (SAVIANI, 2005, p. 13).

A própria identificação e consequente seleção, dentre o acervo cultural produzido pela humanidade, dos conteúdos a serem convertidos em saber escolar para efeitos de ensino e aprendizagem e, conjuntamente, as formas mais adequadas para objetivação do processo de transmissão e apropriação desses saberes, já é resultante de uma decisão teórico-metodológica, ou seja, implica a adesão, conscientemente ou não, a uma determinada concepção pedagógica que, por sua vez, sustenta-se em determinados pressupostos ontológicos, gnosiológicos e axiológicos, ou seja, numa concepção de mundo.

Infere-se, dessa assertiva, que a teoria é condição para a organização sistemática e intencional da educação que, na sociedade moderna, sobretudo após a revolução industrial, é convertida numa questão social que exige, para seu equacionamento, uma práxis intencional coletiva, ou seja, a criação de um sistema de educação (SAVIANI, 2009).

O produto intencional e concreto de uma práxis intencional coletiva, eis o que está sendo denominado "sistema". Vê-se, pois, que a teoria não faz o sistema; ela é apenas uma condição necessária para que ele se faça. Quem faz o sistema são os homens, quando assumem a teoria em sua práxis. E quem faz o sistema educacional são os educadores quando assumem a teoria na sua práxis educativa, isto é, quando sua prática é orientada teoricamente de modo explícito (idem, p. 42).

Sendo o trabalho educativo uma atividade específica cuja finalidade, numa perspectiva emancipatória, consiste na humanização de cada ser humano singular, o objeto da atividade de ensino e aprendizagem consiste no acervo cultural que representa o mais alto nível de desenvolvimento humano, ou seja, a cultura letrada, sistemática, científica. Tendo claro o objeto e finalidade do trabalho pedagógico, cumpre identificar os meios 
(materiais, conceituais e técnicos) disponíveis e mais adequados que permita efetivar uma prática pedagógica adequada às finalidades estabelecidas. No entanto, ressalta-se, o processo de trabalho, tal qual nos lembrou Paro (2000), incluindo o educativo, é um trabalho social o que implica afirmar que sua consecução depende do esforço coletivo intencional, ou, como afirmou Saviani, de uma práxis intencional coletiva que só se efetiva quando cada educador singular se apropria de uma teoria e a assume em sua prática pedagógica, além de adquirir uma atitude de vigilância reflexiva constante.

Contudo, cabe, nesse momento, um questionamento sobre as condições reais, concretas de realização de uma educação tal qual anunciada visto que, até o momento, no Brasil, impõe como luta a organização de um Sistema Nacional de Educação que tenha como finalidade precípua a promoção, de fato e não só de direito, do pleno desenvolvimento de cada ser humano singular.

\section{Os limites do trabalho coletivo na Escola Moderna: divisão do trabalho pedagógico na história da educação brasileira}

A história da educação brasileira evidencia que é somente em 1827 que o poder central manifesta preocupação com a instrução sistematizada com a promulgação da Lei de 15 de outubro na qual se determina a criação de escolas de primeiras letras "em todas as cidades, vilas e lugares mais populosos que forem necessários". Mas a ação do governo imperial não ia além disso, não sendo previsto, portanto, condições materiais para que essa lei se efetivasse. Pouco depois, em 1834, por meio de um Ato Adicional, estabelece-se a descentralização passando a educação a ser responsabilidade das províncias, com exceção do ensino superior. Nesse contexto, o processo de organização da educação escolar no Brasil Império é moroso e pouco significativo.

É somente após a proclamação da República, objetivando influir na formação do homem adequado à "nova" ordem sócio-política e econômica que "o poder público assume a tarefa de organizar e manter integralmente escolas, tendo como objetivo a difusão do ensino a toda a população" (SAVIANI, 2004, p. 18).

Nesse momento o Estado de São Paulo toma a dianteira e, sob o governo de Prudente de Morais, tem início a primeira reforma da instrução pública conhecida como Reforma Caetano de Campos, em 1890, começando pela Escola Normal e, em 1892, com a instrução geral. Instituem-se, a partir desse momento, os grupos escolares também chamados de escolas graduadas, a partir da reunião das escolas isoladas.

Cada grupo escolar tinha um diretor e tantos professores quantas escolas tivessem sido reunidas para compô-lo. Na verdade essas escolas isoladas, uma vez reunidas, deram origem, no interior dos grupos escolares, às classes que, por sua vez, correspondiam às séries anuais. Portanto, as escolas isoladas eram não-seriadas, ao passo que os grupos escolares eram seriados (SAVIANI, 2007, p. 172).

Com a organização dos grupos escolares tem-se, pela primeira vez na história da educação brasileira, a divisão do trabalho pedagógico por meio da divisão do processo em séries anuais. Surge, assim, a necessidade de organização e administração coletiva do processo de ensino e aprendizagem visto que cada professor era responsável somente por uma parcela (anual) do trabalho educativo. Eis porque, na estrutura dos grupos escolares era prevista a figura do diretor a fim de que cumprisse o papel de coordenação do esforço coletivo dos educadores visando uma mesma finalidade. 
Conforme as transformações se processavam na sociedade brasileira, novas ideias sobre a necessidade de formação das novas gerações eram gestadas e, com isso, novas propostas eram elaboradas no sentido de se ampliar a oferta de instrução pública. A década de 1920 é simbólica nesse sentido, visto que várias reformas pontuais foram sendo desenvolvidas em várias regiões do Brasil, como afirma Tanuri (2000, p. 70);

[...] no Ceará, quando da reforma ali realizada por Lourenço Filho (Decreto 474, de 21/1/1923); na Bahia, quando da reforma realizada por Anísio Teixeira (Lei 1.846, de 14/8/1925); em Pernambuco, na reforma realizada por Carneiro Leão (Ato 1.239, de 27/12/1928 e Ato 238, de 9/2/1929); no Distrito Federal, na reforma realizada por Fernando de Azevedo (Decreto 3.281, de 23/1/1928 e 2.940, de 22/11/1928); em Minas Gerais, na reforma ali realizada por Francisco Campos e Mário Casasanta (Decreto 7.970-A, de 15/10/1927).

Dessas reformas, destaca-se a empreendida por Fernando de Azevedo no Distrito Federal, como atesta Lourenço Filho num artigo publicado em "O Estado de São Paulo" em 15 de junho de 1928 ao considerá-la como uma "reconstrução total do aparelho, desde as escolas singulares à escola normal, remodelando também os institutos profissionais do Distrito Federal" (apud Azevedo, 1963, p. 648, nota 27). Apesar de se restringir ao Distrito Federal, essa reforma estabeleceu os princípios organizacionais para a educação nacional, baseada numa abordagem técnica e científica da administração da educação escolar. Assim se manifesta o próprio Fernando de Azevedo sobre a referida reforma por ele empreendida (1963, p. 649):

Não foi uma reforma de "superfície", de caráter administrativo ou de pura renovação de técnicas, mas uma reforma radical, feita em profundidade, e montada para uma civilização industrial, e em que, tomando-se o sentido da vida moderna e das necessidades nacionais, se procurou resolver as questões técnicas em função de uma nova concepção de vida e da cultura e, portanto, de novos princípios e diretrizes de educação.

Tem-se início, aqui, a transposição das ideias sistematizadas na chamada Administração Científica à educação, reforçada com o advento do Estado Novo no qual a centralização e o controle administrativo-pedagógico são erigidos em princípios fundamentais de gestão da educação nacional.

O precursor, no Brasil, dos estudos sobre Administração Escolar foi Roldão Lopes de Barros, tipógrafo, normalista pela Escola Normal da Praça (São Paulo) e, posteriormente, com a transformação da Escola Normal de São Paulo em Instituto de Educação, passa a professor com a incumbência de sistematizar os estudos a partir das ideias de Taylor e Fayol tendo ministrado, inclusive, cursos de administração para os diretores dos grupos escolares por meio dos quais as ideias e práticas da administração científica foram introduzidas na organização e gestão das escolas, naquele momento. José Querino Ribeiro, como discípulo de Roldão, continua seu trabalho sobre administração escolar.

Taylor ${ }^{5}$, no final do século XIX e início do XX, desenvolveu estudos sistemáticos sobre processos de trabalho buscando maximizar a produção com o mínimo de dispêndio possível. Para isso analisou as etapas da linha de produção, identificando suas partes constitutivas, o tempo e o movimento que correspondiam a cada momento do processo. Desse estudo emergiram alguns princípios de organização racional do trabalho tais como a 
divisão do trabalho em elementos simples e, consequentemente, a especialização do trabalhador na tarefa que lhe caberia no processo de trabalho, separação entre o momento da concepção e execução, necessidade de supervisão, de instrução adequada das tarefas a serem cumpridas por cada trabalhador. Taylor admitia ser possível a generalização dos princípios da administração por ele formulados considerando, contudo, que cada processo de trabalho deveria ser analisado meticulosamente a fim de identificar a melhor forma de organizá-lo buscando maximizar os resultados do processo. Assim sintetiza José Querino Ribeiro (1978, p. 133/134) o trabalho desenvolvido por Taylor:

[...] foi Taylor o primeiro a fazer uma análise completa do cargo ou função, desdobrando-o em suas partes componentes. Procedeu à sua divisão e subdivisão, chegando, finalmente, aos movimentos necessários a cada operação os quais em seguida cronometrou. Estabeleceu então padrões de execução do trabalho e experimentou-os. Assim descobriu Taylor que o trabalho pode ser executado melhor e mais economicamente através da subdivisão das funções. $O$ trabalho de cada pessoa na organização deveria, tanto quanto possível, se limitar à execução de uma única tarefa predominante.

Fayol $^{6}$, contemporâneo de Taylor, também se debruçou sobre a questão da organização racional do trabalho objetivando aumentar a produtividade com o mínimo de custo, enfatizando a estrutura organizacional da empresa e o papel importante da administração na direção, coordenação e controle do processo produtivo. Eis a síntese da contribuição de Fayol à administração:

Fayol, por sua vez, ao descrever a organização propusera a divisão do trabalho como um dos princípios da administração. Para esse autor "a divisão do trabalho permite reduzir o número de objetivos sobre os quais devem ser aplicados a atenção e o esforço. Reconhece-se que essa é a melhor maneira de obter o máximo proveito do indivíduo e da coletividade. Não se aplica somente às tarefas técnicas senão a todos os trabalhos, sem exceção, que põem em movimento um número mais ou menos grande de pessoas e que delas exigem diferentes classes de aptidões. Tende, em consequência, à especialização das funções e à separação dos poderes" (RIBEIRO, idem, p.134).

Com o ideário renovador, assim, são introduzidos, como já assinalado, os conceitos e técnicas originados do campo da administração de forma direta ao campo educacional e, com o advento da concepção produtivista que passa a ser a orientação hegemônica a partir da década de 1960, esse processo só vem a se acentuar, considerando que esta se apoia na teoria do capital humano para a qual o ser humano é convertido, no processo produtivo, em um recurso tal qual outros necessários no processo de produção de mercadorias que, portanto, precisa ser racionalmente administrado buscando o mínimo de dispêndio e o máximo de produtividade no menor tempo possível a fim de fomentar a acumulação de capital.

Como se percebe pelas análises até aqui desenvolvidas, a atividade de administração tem sua origem no processo produtivo em decorrência da divisão do trabalho que se instaura no modo de produção capitalista a fim de alavancar a produtividade com menor dispêndio de recursos no menor tempo possível, num processo intencional e sistemático de subordinação do trabalho e, consequentemente, do trabalhador, aos interesses do capital. 
O processo de divisão do trabalho sob os moldes capitalistas promove uma crescente fragmentação tanto das atividades humanas quanto das finalidades/objetivos do processo de trabalho resultando, assim, num processo sistemático de especialização. A fim de garantir o controle do processo estabelecido nesses moldes, emergem como necessidade atividades específicas cujo papel é controlar o processo produtivo de modo geral e, mais especificamente, os próprios trabalhadores.

Vê-se que, ao longo da história da educação, a transposição das ideias e instrumentos de administração (ou gestão) de empresas para o campo educacional vem promovendo uma fragmentação cada vez mais acentuada do trabalho educativo, no qual cada profissional é impelido, pelas condições de trabalho e de formação, a dominar somente os objetivos e técnicas necessários para o desenvolvimento da parte que lhe cabe no processo perdendo, assim, a finalidade para a qual devem convergir todos os esforços dos educadores, independente do lugar que ocupam na estrutura organizacional da escola.

Além desse aspecto da divisão do trabalho pedagógico acima indicado, outro merece destaque, pois, sem ele, nenhuma política educacional ou projeto se efetiva na escola. Trata-se do controle ideológico dos trabalhadores da educação levado a cabo por meio dos processos de formação tanto inicial quanto continuada, além de outros mecanismos instaurados, sobretudo a partir da década de 1990.

No processo de formação inicial, há algumas décadas, disseminou-se um ideário, primeiro pela Escola Nova e, depois, pelos adeptos das teorias do "aprender a aprender", de que o conhecimento é construído por cada sujeito individual por meio das suas próprias experiências de vida secundarizando ou, chegando ao extremo, negando a possibilidade e necessidade do trabalho do professor. Essas ideias resultaram de um esvaziamento gradativo de conteúdos teóricos organicamente articulados no processo de formação inicial, pois o entendimento, nessa perspectiva, é de que o professor se forma na própria prática da profissão docente. Um profissional com poucos e pouco consistentes instrumentos teóricos que lhe permitam analisar os desafios que a prática pedagógica lhe impõe cotidianamente limitando, assim, a elaboração de respostas adequadas aos problemas enfrentados, torna-se presa fácil para um processo chamado de formação continuada desenvolvida cada vez mais pelo Estado, por meio das secretarias de educação, mas que, verdadeiramente, se constituem em cursos de treinamento para implementação das políticas educacionais elaboradas pelos técnicos da educação, tal qual o Programa Ler e Escrever do Estado de São Paulo, dentre outros que se espalham por várias partes do Brasil.

Outros aspectos poderiam ser explorados. No entanto, entende-se que os dois aventados já dão conta de explicitar o que se pretende nesse item que consiste no apontamento dos limites concretos para realização de um trabalho intencional coletivo no interior das escolas como pressuposto para o desenvolvimento de um projeto de educação que se pretenda ter o ser humano como finalidade. $\mathrm{O}$ primeiro aspecto, a divisão do trabalho pedagógico, indica que se perdeu, por parte dos educadores, ao longo do tempo, a finalidade do processo educativo do qual todos participam conscientes, contudo, somente dos objetivos específicos circunscritos ao lugar que ocupam na organização escolar. $\mathrm{O}$ outro aspecto refere-se ao esvaziamento dos fundamentos teóricos que permitem uma prática pedagógica coerente, consistente e eficaz por parte dos trabalhadores da educação, o que os deixam suscetíveis a adesão aos programas estruturados pelo Estado, bem como por outros grupos que se dizem "amigos" da escola mas que, de fato, tem outros objetivos que não são educacionais como, por exemplo, os donos das grandes empresas privadas educacionais que criaram "sistemas de ensino" apostilados e vem, nos últimos anos, tendo alta lucratividade com a venda da "mercadoria" educação. 
Percebe-se, claramente, que a forma que assume a instituição escolar e as características do trabalho pedagógico desenvolvido no seu interior está em consonância com os contornos do trabalho, de modo geral, e do Estado moderno. Isso significa que, assim como qualquer outra esfera social, também a escola pública (estatal)surge, se estrutura e se desenvolve marcada pelas contradições e antagonismos essenciais resultantes do modo de produção capitalista.

Mas, afinal, há alguma possibilidade real de ultrapassar os limites dessa situação no sentido de construção de um projeto de educação coletivo e efetivamente humanizador?

\section{As possibilidades do trabalho coletivo na Escola Moderna: as lutas necessárias}

O caminho até aqui percorrido indica, de um lado, a necessidade histórica que se impõe de humanização das novas gerações de forma consciente, coerente e consistente e que esse trabalho só é possível alcançar por meio de uma práxis intencional coletiva. Esta, por sua vez, só é possível com a clareza da finalidade do processo de trabalho pedagógico por parte de todos os profissionais que concorrem para a consecução desse intento considerando o ser humano desde seu nascimento até sua fase adulta.

Além disso, como os estudos sobre administração alertou, o processo de trabalho adequado a determinada finalidade é constituído pelo objeto e meios necessários a serem utilizados para, agindo sobre e a partir do objeto, se alcance o objetivo final almejado.

No caso da educação, portanto, exige-se conhecimentos teóricos e práticos sobre o próprio homem como ser social e historicamente constituído, ou seja, situado o que implica a necessária compreensão da própria sociedade em que o ser humano está inserido; o domínio dos elementos culturais que devem ser objeto de ensino e aprendizagem para a promoção do desenvolvimento humano no sentido de sua emancipação e, também, das formas por meio das quais é possível promover o processo de transmissão-assimilação desses saberes. Todos esses conhecimentos, contudo, devem ser articulados a partir de um mesmo sistema conceitual que lhe dê coerência e consistência que, a nosso ver, a pedagogia histórico-crítica se apresenta, na atualidade, como a única teoria formulada que fornece os pressupostos necessários para uma prática pedagógica coletiva nesse sentido.Cumpre, portanto, como parte da luta por uma educação pública, gratuita, laica e de qualidade para todos, por parte de todos os pesquisadores e professores aglutinados pela e em torno da pedagogia histórico-crítica a tarefa de elaborar, seja no âmbito das instituições de ensino superior nas quais atuem, seja no das secretarias de educação, cursos de formação que subsidiem teórica e praticamente, de forma sólida e consistente, os educadores (professores, diretores, coordenadores, supervisores) dos diferentes níveis e modalidades de ensino. A teoria, ao realizar o papel de instrumentalizar os sujeitos para a compreensão da realidade e o enfrentamento dos problemas postos pela prática, cumpre um papel unificador, imprescindível para uma práxis intencional coletiva.

No entanto, a formação não é suficiente para o enfrentamento dos desafios postos pela estrutura educacional na atualidade. Aqui se faz mais do que necessária, urgente, a construção de uma pauta de luta por melhores condições de trabalho que extrapole os limites corporativos e unicamente salariais e que, a nosso ver, deve ser encampada pelas entidades sindicais com a efetiva participação dos professores na sua elaboração. É claro que a remuneração é um fator importante e deve continuar a ser perseguido mas, inclusive, como estratégia para fortalecer a luta, por exemplo, a questão da jornada de trabalho integral em uma única escola é uma questão que deve ser insistentemente perseguida, considerando, ao menos, $50 \%$ do tempo em sala de aula e os outros $50 \%$ para planejamento e estudo, não necessariamente na escola e não aceitando, de forma alguma, 
os mecanismos de implementação de redução de jornada tal qual vem se efetivando nas diferentes redes de ensino que, grosso modo, não garante, de forma efetiva, tempo para atividades extraclasse.

Como já indicado ao longo do texto, a escola é uma instituição social e, como tal, guarda uma relação de interdependência e reciprocidade com a sociedade como um todo. A luta por uma educação (estatal) efetivamente pública passa pela luta por uma outra sociedade. Isso implica não limitar a ação aos muros da escola e sim articulá-la aos movimentos sociais mais amplos em torno da construção coletiva de um projeto societário alternativo. É necessário, assim, materializar uma participação social substantiva a fim de garantir um controle social efetivo e o desvelamento das contradições e antagonismos inerentes à sociedade moderna.

Nesse sentido, parece-nos oportuno buscar inspiração em alguns teóricos. Gramsci (2004), por exemplo, afirmou queo controle se apresentava, aos operários, como uma questão essencial para sua organização política enquanto classe:

O terreno do controle, portanto, aparece como o fundamento sobre o qual a classe operária - tendo conquistado a confiança e o consentimento das grandes massas populares - constrói o seu Estado, organiza as instituições do seu governo, chamado para integrá-lo todas as classes oprimidas e exploradas, e inicia o trabalho positivo de organização do novo sistema econômico e social(idem, p. 2).

Importa lembrar que, no final da década de 1970 e durante, sobretudo, os anos de 1980, os educadores ocuparam um lugar central na luta por uma sociedade mais justa e igualitária, levando como bandeira a defesa da escola pública. Como uma das estratégias, tendo na memória os anos de ditadura civil-militar, foi a garantia, na Constituição Federal de 1988, de que o Estado, obrigatoriamente, seria regido por uma gestão democrática e, para isso, buscou-se ampliar os mecanismos de controle social por meio de conselhos nas diferentes esferas da educação, tanto no interior das escolas quanto no âmbito mais amplo da administração pública.

No entanto, como já alertado, a participação popular tende a ser permitida, em determinadas circunstâncias históricas, de forma, contudo, regulada traduzida numa democracia meramente formal e não efetiva que tende a se converter em instrumento de legitimação de propostas elaboradas pela ideologia dominante. Faz-se necessário, portanto, buscar caminhos para superação dessa condição de participação e, parece-nos, a escola pode ter um papel relevante a cumprir.

Ciente das posições diametralmente opostas sobre o papel da escola nas transformações sociais tendo, de um lado, aqueles que advogam que as grandes mudanças só ocorreriam no seio da sociedade sendo necessário, portanto, sair da escola e, de outro, os que preceituam o valor salvacionista da educação, concordamos com Fernandes (2010) de que há mudanças que se principiam no interior das instituições e podem tomar dimensão tal que provocam mudanças mais amplas e substantivas. Defende Fernandes que:

O professor não pode estar alheio a essa dimensão. Se ele quer mudança, tem de realizá-la nos dois níveis - dentro da escola e fora dela. Tem de fundir seu papel de professor ao seu papel de cidadão - e se for levado, por situação de interesses e por valores, a ser um conservador, um reformista ou um revolucionário, ele sempre estará fundindo os dois papeis (idem, p. 128). 
[...] mudança implica luta e luta social. Se o conservador quer mudar alguma coisa, quer fazê-lo para preservar suas posições de poder, ou então, para amplificá-las, para não correr riscos; o reformista quer mudar para conquistar posições de poder; por sua vez, o revolucionário quer mudar porque se identifica com classes que são portadoras de ideias novas a respeito da natureza, do conteúdo da civilização e da natureza do homem (ibidem, p. 131).

Ressalta, ainda, Fernandes, que, dadas as características do Brasil, país fortemente marcado pelas desigualdades sociais, os professores, mais até que os próprios políticos ou qualquer outro sujeito social, são aqueles que se deparam, cotidianamente, com as misérias sociais produzidas por uma sociedade organizada sobre o modo de produção capitalista de caráter dependente. O trabalho docente, nessas circunstâncias peculiares, reveste-se, portanto, de um caráter essencialmente político. Isso porque a escola, como toda instituição social, não é neutra.

Assumindo-se como um agente revolucionário, o professor se confrontará, sempre, com as condições objetivas de exercício profissional que tendem a enclausurá-lo nos limites estabelecidos pela ordem vigente à educação escolar que se pretende para a maioria da população.

Assim, a luta pela construção de um projeto de educação que, efetivamente, atenda as necessidades e interesses da maioria da população brasileira passa, necessariamente, pela luta pela transformação social. E mais. Considerando, ao concordar com Florestan Fernandes, que o professor é um sujeito social, na particularidade brasileira, cumpridor de um importante papel político, há que se articular à luta mais ampla a luta por melhores condições de trabalho e de formação. Afinal, o "educador também precisa ser educado".

\section{Referências}

AZEVEDO, Fernando. A Cultura Brasileira: introdução ao estudo da cultura no Brasil. 4 ed. Brasília: Editora da Universidade de Brasília, 1963.

AZILDE, L. A.; LOMBARDI, J. C.; MINTO, L. W. (orgs). História da Administração Escolar no Brasil: do diretor ao gestor. Campinas, SP: Editora Alínea, 2010.

COUTINHO, Luciana Cristina Salvatti. Apontamentos sobre o processo de reestruturação do Sistema Público Municipal de Educação de Limeira-SP. Germinal: Marxismo e Educação em Debate, Salvador, v. 5, n. 2, p. 175-189, dez 2013.

ENGELS, F. A origem da família, da propriedade privada e do Estado. 2 ed. Rio de Janeiro: Ed. Vitória, 1964.

FERNANDES, Florestan. A formação política e o trabalho do professor. In OLIVEIRA, Marcos Marques de. Florestan Fernandes. Recife: Fundação Joaquim Nabuco, EditoraMassangana, 2010.

GRAMSCI, A. Escritos Políticos. Vol2. Brasil: Editora Civilização Brasileira, 2004.

LEONTIEV, Alexis. O desenvolvimento do psiquismo. Lisboa: Horizonte, 1978.

MARX, Karl. O capital: crítica da economia política. Livro I: o processo de produção do capital. São Paulo: Boitempo, 2013.

MINTO,Lalo Watanabe. As reformas do Ensino Superior no Brasil: o público e o privado em questão. Autores Associados, 2006. 
OLIVEIRA, Marcos Marques de. Florestan Fernandes. Recife: Fundação Joaquim Nabuco, EditoraMassangana, 2010.

PARO, Vitor Henrique. Administração Escolar: introdução crítica. 9 ed. São Paulo: Cortez, 2000.

RIBEIRO, José Querino. Ensaio de uma teoria da administração escolar. São Paulo: Saraiva, 1978.

SANFELICE, José Luís. Estado e Política Educacional. In LOMBARDI, José Claudinei (org). Temas de pesquisa em educação. Campinas, SP: Autores Associados, 2003; HISTEDBR; Caçador, SC: UnC, 2003.

SAVIANI, Dermeval. Pedagogia histórico-crítica: primeiras aproximações. 9 ed. Campinas, SP: Autores Associados, 2005.

Autores Associados, 2000.

Educação brasileira: estrutura e sistema. 8 ed. Campinas, SP:

Educação: do senso comum à consciência filosófica. 13 ed.

Campinas, SP: Autores Associados, 2000a.

Escola e democracia: teorias da educação, curvatura da vara, onze teses sobre educação política. 39 ed. Campinas, SP: Autores Associados, 2007.

Sistema de Educação: subsídios para a Conferência Nacional de Educação (CONAE). In QUEIROZ, A. C. e GOMES, I. (orgs). Conferência Nacional de Educação (Conae), 2010: reflexões sobre o Sistema Nacional Articulado de Educação e o Plano Nacional de Educação. Brasília: Instituto Nacional de Estudos e Pesquisas Educacionais Anísio Teixeira, 2009.

SAVIANI, Dermeval e DUARTE, Newton (orgs). Pedagogia histórico-crítica e luta de classes na educação escolar. Campinas, SP: Autores Associados, 2012.

TANURI, Leonor Maria. História da formação de professores. Revista Brasileira de Educação, n. 14, 2000.

\section{Notas}

\footnotetext{
${ }^{1}$ Professora Adjunta do Departamento de Ciências Humanas e Educação da UFSCar - campus Sorocaba. Pesquisadora dos Grupos de Pesquisa HISTEDBR/GT Unicamp e NEPHEB/UNIVÁS.

${ }^{2}$ Professor livre-docente do Departamento de Filosofia e História da Educação da Faculdade de Educação da Unicamp. Coordenador executivo do Grupo de Estudos e Pesquisas HISTEDBR.

${ }^{3}$ Não é possível aprofundar aqui o processo de divisão social do trabalho e sua relação com a produção da consciência. Sugere-se, assim, as seguintes leituras: A Ideologia Alemã (Marx e Engels) e O Capital (Marx).

${ }^{4}$ Sugestão de leitura: A origem da família, da propriedade privada e do Estado (Engels).

${ }^{5}$ A obra principal e mais conhecida de Frederick Taylor foi publicada em 1911 com o título "Princípios da Administração Científica"

${ }^{6}$ Administração Industrial e Geral é considerada a principal obra de Henri Fayol publicada em 1916.
}

Recebido: $\quad$ março-16 Aprovado: $\quad$ setembro-16 